\title{
A Comparison of Distillery Stillage Disposal Methods
}

\author{
V. Sajbrt, M. Rosol, P. Ditl
}

\begin{abstract}
This paper compares the main stillage disposal methods from the point of view of technology, economics and energetics. Attention is paid to the disposal of both solid and liquid phase. Specifically, the following methods are considered: a) livestock feeding, b) combustion of granulated stillages, c) fertilizer production, d) anaerobic digestion with biogas production and e) chemical pretreatment and subsequent secondary treatment. Other disposal techniques mentioned in the literature (electrofenton reaction, electrocoagulation and reverse osmosis) have not been considered, due to their high costs and technological requirements.

Energy and economic calculations were carried out for a planned production of $120 \mathrm{~m}^{3}$ of stillage per day in a given distillery. Only specific treatment operating costs (per $1 \mathrm{~m}^{3}$ of stillage) were compared, including operational costs for energy, transport and chemicals. These values were determined for January $31^{\text {st }}, 2009$.

Resulting sequence of cost effectiveness: 1. - chemical pretreatment, 2. - combustion of granulated stillage, 3. - transportation of stillage to a biogas station, 4. - fertilizer production, 5. - livestock feeding.

This study found that chemical pretreatment of stillage with secondary treatment (a method developed at the Department of Process Engineering, CTU) was more suitable than the other methods. Also, there are some important technical advantages. Using this method, the total operating costs are approximately $1150 € /$ day, i.e. about $9,5 € / \mathrm{m}^{3}$ of stillage. The price of chemicals is the most important item in these costs, representing about $85 \%$ of the total operating costs.
\end{abstract}

Keywords: disposal of distillery stillage, economic comparison, energy requirements.

\section{Introduction}

One of the most important problems in distilling is further processing or disposing of distillation residues, known as stillage or slops. The urgency of finding a solution for this issue increases with growing production of ethanol. Nowadays, minimization of all energy losses and efficient use of waste (stillage in this case) are modern trends in all production facilities. This work deals with ways of processing stillage in the distillery under study. Energy and financial calculations were carried out for the planned production of $120 \mathrm{~m}^{3}$ of stillage per day. Only specific treatment operating costs (per $1 \mathrm{~m}^{3}$ of stillage) were compared, including operational costs of energy, transport and chemicals.

\section{A description of ethanol production}

There are two main methods of ethanol production.

The Chemical method, used in the chemical industry. This mainly involves ethylene hydratation: $\mathrm{CH}_{2}=\mathrm{CH}_{2}+\mathrm{H}_{2} \mathrm{O} \rightarrow \mathrm{C}_{2} \mathrm{H}_{5} \mathrm{OH}$. Ethanol produced in this way is not suitable for consumption, because of harmful ingredients contained in it.

The Biological method, used in distilleries. This method consists of fermentation and distillation of suitable biological substrates, which must contain saccharides. Only ethanol produced in this way is suitable for human consumption.
There are many primary raw materials suitable for ethanol production. Only those containing a sufficient amount of starch are used in the distillery under study. Starch is a polysaccharide with the formula $\left(\mathrm{C}_{6} \mathrm{H}_{10} \mathrm{O}_{5}\right)_{\mathrm{n}}$, consisting of two different polysaccharides: amylose and amylopectin. These polysaccharides consist of thousands of glucose molecules. The main raw materials used in the distillery are potatoes and cereals (wheat, rye, maize, sometimes barley and oats). Residues from potato food production are also used for ethanol production. Sugar beet is another substrate suitable for ethanol production, but it is not used in this distillery.

At the beginning of the process, the input raw material is disintegrated into a mash containing particles from 0.4 to 1.2 millimeters. Then an enzyme, $\alpha$-amylasa, is added and the batch is heated up to 90-94 ${ }^{\circ} \mathrm{C}$. The starch contained in the mash becomes a gelatinous liquid. Then the mash is pumped into tanks together with another enzyme, $\beta$-amylasa. This enzyme breaks starch down into glucose molecules. The mash must be cooled down to $30-35^{\circ} \mathrm{C}$, and then it is pumped into the fermentation tanks. After the addition of fermentative microbial cultures (inoculation), fermentation begins. During this process, glucose is biologically transformed into the final product - ethanol - in anaerobic conditions. This process takes approximately 48-72 hours. There are many biochemical reactions running in the process. The most important chemical reaction can be written as:

$$
\mathrm{C}_{6} \mathrm{H}_{12} \mathrm{O}_{6} \rightarrow 2 \mathrm{C}_{2} \mathrm{H}_{5} \mathrm{OH}+2 \mathrm{CO}_{2}
$$


meaning that during ideal and maximum fermentation of $1 \mathrm{~kg}$ of glucose, $0.511 \mathrm{~kg}$ of ethanol and $0.489 \mathrm{~kg}$ of carbon dioxide originate. However, approximately 6-8 wt. \% of the glucose contained in the mash is consumed for growth of the fermentative microbial cultures.

After fermentation there is $6-9$ wt. \% of ethanol in the mash. The product is separated from the mash in a distillation column. Crude spirit flows out from the top of the column, and stillage flows out from the bottom. The crude spirit must be refined in special refining columns to produce refined ethanol. This ethanol is suitable for producing alcoholic beverages.

\section{Stillage}

There are two basic waste products from fermentation - solid parts of the input material, and the liquid fraction, i.e. stillage.

According to [1]: "Alcohol distillery stillage (the remains after distillation of fermented mash) is the main, high-strength 'waste' from distillation. The production of stillage in the distillery is in the range of 10-14 $\mathrm{m}^{3}$ per $1 \mathrm{~m}^{3}$ of pure ethanol. This waste contains between $5-8$ wt. \% of dry mass, is moderately acidic (with $\mathrm{pH}$ about 4 ) and has a high chemical oxygen demand value (COD of about $50000 \mathrm{mg}$ per liter). Dried stillage from cereal is often used as a feed for livestock, containing about $30 \%$ of proteins. Unfortunately, it is complicated to feed wet stillage, because it is an organic material. Nowadays, stillage is used for livestock feeding or it is used for energy production in biogas plants."

\section{Stillage disposal methods}

There is only one initial condition for all methods compared here - average planned production of stillage of $120 \mathrm{~m}^{3}$ per day with dry mass concentration of $5 \mathrm{wt} . \%$.

All cost calculations are based on the following assumptions:

- Machinery power input: centrifuge (all methods) - $20 \mathrm{~kW}$, agitation system (chemical pretreatment) - $1.5 \mathrm{~kW}$, hydrostatic pump (chemical pretreatment) $-10 \mathrm{~kW}$.

- $1 \mathrm{kWh}$ of electric energy costs $3.30 \mathrm{CZK}(0.13 €)$.

- Thermal energy for stillage concentration or drying is obtained from combustion of natural gas (all methods with an evaporator or a dryer). The efficiency of the gas boiler is $90 \%, 1 \mathrm{Nm}^{3}$ of natural gas costs $9.50 \mathrm{CZK}(0.36 €)$.

- $1 \mathrm{~kg}$ of $\mathrm{Ca}(\mathrm{OH})_{2}$ for stillage neutralization costs 3.80 CZK $(0.15 €)$.

- 1 hour of tractor work (fertilization of fields) costs 450 CZK $(17.30 €)$.

- $1 \mathrm{~km}$ of truck driving costs 32 CZK $(1.23 €)-$ transportation to a biogas plant.

- The biogas yield from $1 \mathrm{~m}^{3}$ stillage with $3 \mathrm{wt} . \%$ is $35 \mathrm{Nm}^{3}$. The electrical efficiency of the CHP unit is $30 \%$ (transportation to a biogas plant).

\section{$5 \quad$ Livestock feeding}

First, there is the possibility of drying wet stillage in a dryer. The end product from drying - dry stillage can be (and usually is) used as a feed or as part of the feed for livestock. Not only livestock, but pigs and sheep (often kept in cooperative farms in the neighbourhood of distilleries) can also be fed with dried stillage. Wet stillage can also be used as a feed, but only until three days after production. After this time, this biological mass degrades, and is not suitable for feeding. Another method of stillage processing as a feed is described in [3]: For example, a French producer of bioethanol, BIO-ETHANOL-NORD PICARDIE, produces granulated dried stillage as a feed. Liquid stillage is cultivated in a special cultivation reactor and enriched with yeast extract. After concentration in an evaporator, mixing with the solid parts follows. This mixture is dryed in dryers. Livestock can be fed with this granulated mass, and meat and bone meal can be substituted by this granulated mass.

The whole process line is drawn in Fig. 1.

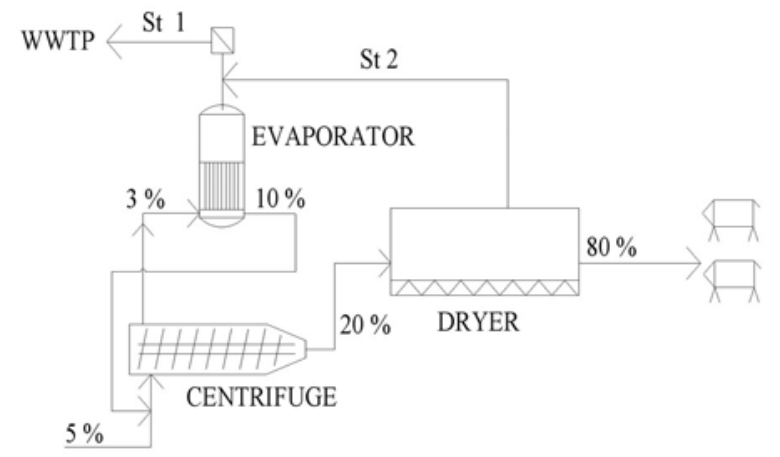

Fig. 1: Livestock feeding process line. Content of dry mass in wt. $\%$

The biggest disadvantage of this method is the high energy demand for evaporation and drying. The total energy requirements for the production of $1 \mathrm{~kg}$ of dried stillage for livestock feeding are the same as the total energy demand for the production of $1 \mathrm{~kg}$ of dried stillage fuel for combustion in boilers, but the combustion provides energy (electric or heat), resulting in potential improvement of the energy balance. Therefore, the stillage feeding method is currently not economically advantageous. Nowadays, the price of conventional feed proteins is similar to the total production costs of evaporated and dried stillage for livestock feeding.

The heart of this method is the concentration of liquid stillage in a centrifuge-evaporator cycle and further drying in a dryer. These two processes (concentration and drying) have the highest total energy de- 
Table 1: All operating costs of the livestock feeding process line

\begin{tabular}{|l|r|l|r|r|l|}
\hline Total cost - electric energy for centrifuge: & 60 & EUR/day & $2.8 \%$ & & \\
\hline Total cost - gas for evaporation: & 1120 & EUR/day & $52.8 \%$ & & \\
\hline Total cost - gas for dryer: & 640 & EUR/day & $30.3 \%$ & & \\
\hline Total transport costs: & 20 & EUR/day & $0.9 \%$ & & \\
\hline Total neutralization costs: & 170 & EUR/day & $8.0 \%$ & & \\
\hline Total costs for pre-treatment of condensate from evaporation: & 110 & EUR/day & $5.2 \%$ & & \\
\hline Purchase of produced feed (dried stillages): & -50 & EUR/day & XXX & & \\
\hline TOTAL OPERATING COSTS: & $\mathbf{2 0 7 0}$ & EUR/day & $100.0 \%$ & $\mathbf{1 7}$ & $\mathrm{EUR} / \mathrm{m}^{3}$ \\
\hline
\end{tabular}

mand share. It is necessary to cool down and condense the vapour from evaporation to an acceptable temperature. This condensate must be pre-treated in a special wastewater treatment plant in the distillery, because of the very high COD value (about $20000 \mathrm{mg} / \mathrm{l}$ ). Then the pre-treated condensate can be drained away to the local wastewater treatment plant, and there it can be processed without any problems. This condensate can also be added to the biomass for biogas production as so-called dilution water. Concentration of stillage is followed by drying and pelleting. However, this is not strictly necessary - concentrated stillage can be used for feeding after neutralization. The number of livestock and pigs in the Czech Republic has been decreasing (since 1990 the number has decreased by approximately one order), and bioethanol (and stillage) production has been increasing. Therefore, the demand for dried stillage in the Czech Republic has been dropping.

Note: There is a great difference between molassesproduced and grain-produced stillage. Molassesproduced stillage can be (and usually is) evaporated up to a dry-weight content of about 35 wt. \%. Grainproduced stillage can be evaporated only to a maximum dry-weight mass value of $10 \mathrm{wt}$. \%, due to problems with fouling and blocking of the mash in the evaporator tubes when reaching a higher dry-weight content. The distillery in this study produces only grain-produced stillage.

Finally, according to [4]: "Livestock can be fed on dry or wet stillage. Feeding on wet stillage may be economically and energetically advantageous, but this method is limited by a short storage period (three days). Wet stillage can be used only for those categories of livestock for which this feeding is acceptable. It depends on specific forage technologies. Dried stillage does not have these restrictions, but the drying process has not only high energy and financial costs but also the risk of damage to the stillage due to excessive temperature. This 'burnt' stillage has less sappiness and a lower quantity of amino acids."
The calculation result of this method is, that the total cost (due to operating costs - energy and transport costs) is $2070 €$ per daily production of stillage. The total operating cost for $1 \mathrm{~m}^{3}$ of stillage is $17 €$. The resulting operating costs are the highest of all disposal methods compared here.

Advantages of this method:

- Sale of the feed $\rightarrow$ savings.

- Lower feed prices for cooperative farms.

Disadvantages of this method:

- High investment costs (evaporator, dryer).

- High operating costs (energy costs).

- Great size of the apparatuses.

\section{Combustion of dried stillage}

Energy can be obtained from combustion of dried corn stillage in biomass boilers (either in a stoker-fired boiler or in a fluidized bed boiler). The production process of fuel for combustion is identical to the production process of granules for feeding. First, the stillage is concentrated in a centrifuge-evaporator cycle, then it is dried in a dryer. The fuel obtained from the dryer can be combusted to gain energy. This energy can be used either for electricity production in steam turbines or for improving the energy balance of the distillery (for heating columns, ldots). The whole process line is drawn in Fig. 2.

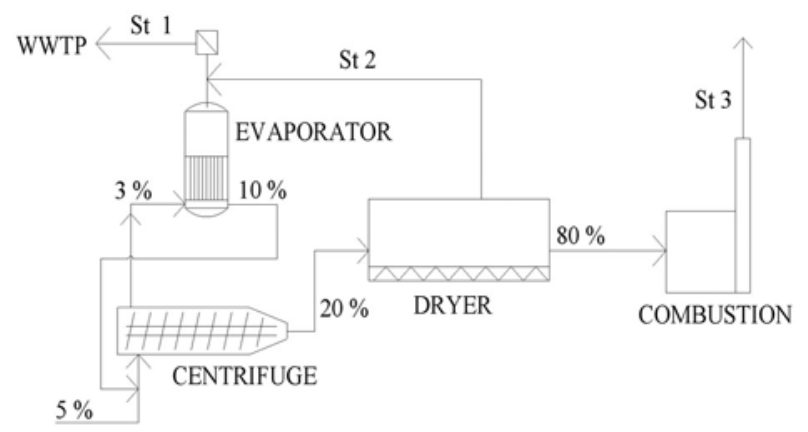

Fig. 2: Combustion process line. Content of dry mass in wt. $\%$ 
Table 2: All operating costs of the combustion process line

\begin{tabular}{|l|r|l|r|l|l|}
\hline Total cost - electric energy for centrifuge: & 60 & EUR/day & $2.9 \%$ & & \\
\hline Total cost - gas for evaporation: & 1120 & EUR/day & $53.3 \%$ & & \\
\hline Total cost - gas for dryer: & 640 & EUR/day & $30.5 \%$ & & \\
\hline Combustion savings - producing of steam: & -780 & EUR/day & XXX & & \\
\hline Total neutralization costs: & 170 & EUR/day & $8.1 \%$ & & \\
\hline Total costs for pre-treatment of condensate from evaporation: & 110 & EUR/day & $5.2 \%$ & & \\
\hline TOTAL OPERATING COSTS: & $\mathbf{1 3 2 0}$ & EUR/day & $100.0 \%$ & $\mathbf{1 1}$ & $\mathrm{EUR} / \mathrm{m}^{3}$ \\
\hline
\end{tabular}

The disadvantage of dried stillage combustion is a high content of sulphur and nitrogen in the burnt gas, which exceed the emission limits. This means that it is necessary to build a desulphurization plant. The main disadvantages of this method are the high investment costs for the production line for fuel production, biomass combustion and burnt gas desulphurisation.

Some advantages: great savings of energy costs and low production of the final waste, ash.

The result of the calculation for this method is that the total operating cost (energy and transport costs) is $1320 €$ per daily production of stillage. The total operating cost for $1 \mathrm{~m}^{3}$ of stillage is $11 €$. This disposal method was found to be the second cheapest of all methods. This is a result of savings due to steam production.

Advantages of this method:

- Energy gain during combustion.

- Small volume of the final waste, ash.

- Relatively low operating costs.

\section{Disadvantages of this method:}

- High investment costs (evaporator, dryer, boilers).

- Great size of the apparatuses.

- Harmful to the environment - exhaust gases.

- The need for a desulphurization plant.

\section{Fertilization by stillage}

If a stillage is used for fertilization, it must be concentrated to a minimum value of $20 \mathrm{wt}$. \% of dry matter. This can be done in a centrifuge-evaporator cycle. The vapour condensate from evaporation must be pre-treated in the WWTP in the distillery. Molassesproduced stillages are most frequently mentioned in the context of fertilizer production, but in fact, all types of stillages are suitable (after neutralization with calcium) for fertilizing fields. The whole process line is drawn in Fig. 3.

Stillage is a rich source of residual sugars, organic nitrogen and other nutrients. This makes it a nutrientrich and ecological fertilizer for agriculture. Stillage, either in its pure state or in combination with straw, can supply or substitute mineral fertilizers. Concen- trated stillage is usually offered cost-free to farmers.

The result of the calculation for this method is that the total operating costs (energy and transport costs) are $1530 €$ per daily production of stillages. The total operating cost for $1 \mathrm{~m}^{3}$ of stillages is $13 €$. This is the second most expensive of all methods compared here, because it generates no earnings.

There is a legislative problem with fertilization by stillage. It is prohibited by law to spread stillage on fields in winter. It can be used for fertilization in summer, but concentrated at least at 20 wt. \%, as mentioned above. According to recent trends, it seems quite possible that fertilization of fields with stillage will be soon prohibited by law throughout the year. The following acts have dealt specifically with these questions: Act No. 254/2001 Coll. on protection of water sources, Act No. 185/2001 Coll. on wastes, which defines stillages as a waste product, and Act No. 334/1992 Coll. on the protection of arable land. This last act strictly prohibits the use of stillages as a fertilizer [2].

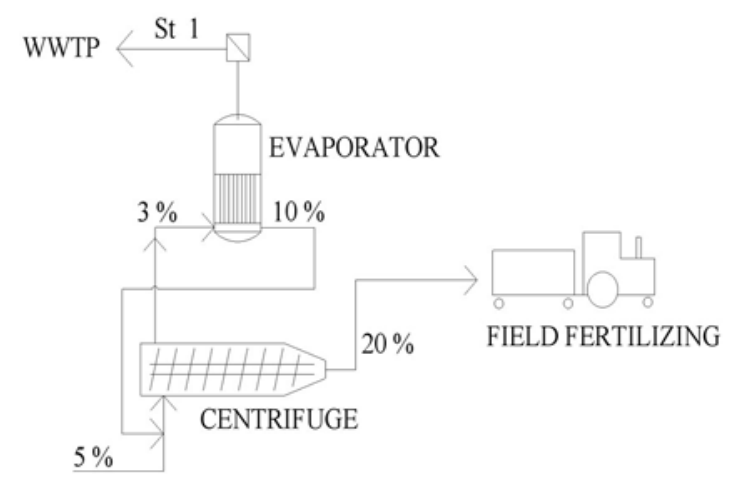

Fig. 3: Fertilizing process line. Content of dry mass in wt. $\%$

\section{Transportation of stillage to a biogas plant}

Biogas is a combination of gases generated during anaerobic digestion (= controlled microbial conversion of organic substances in anaerobic conditions to pro- 
Table 3: All operating costs of the fertilizing process line

\begin{tabular}{|l|r|l|r|r|r|}
\hline Total cost - electric energy for centrifuge: & 60 & EUR/day & $3.9 \%$ & \\
\hline Total cost - gas for evaporation: & 1120 & EUR/day & $73.2 \%$ & & \\
\hline Total transport costs on the fields: & 70 & EUR/day & $4.6 \%$ & & \\
\hline Total neutralization costs: & 170 & EUR/day & $11.1 \%$ & & \\
\hline Total costs for pre-treatment of condensate from evaporation: & 110 & EUR/day & $7.2 \%$ & & \\
\hline TOTAL OPERATING COSTS: & $\mathbf{1 5 3 0}$ & EUR/day & $100.0 \%$ & $\mathbf{1 3}$ & $\mathrm{EUR} / \mathrm{m}^{3}$ \\
\hline
\end{tabular}

duce biogas and digestate). The usual composition of biogas is: $40-75 \%$ of methane $\mathrm{CH}_{4}, 25-55 \%$ of carbon dioxide $\mathrm{CO}_{2}, 0-10 \%$ of water vapour $\mathrm{H}_{2} \mathrm{O}, 0-5 \%$ of nitrogen $\mathrm{N}_{2}$, and the rest is a mixture of hydrogen $\mathrm{H}_{2}$, ammonia $\mathrm{NH}_{3}$ and hydrogen sulphide $\mathrm{H}_{2} \mathrm{~S}$. Only methane and hydrogen are interesting from the energetic point of view. The problematic components are hydrogen sulphide and ammonia. It is usually neccesary to remove these components from biogas to protect the CHP unit. The most frequently used agricultural waste as an input mass for fermentation are: manure, slurry and maize. These materials are acceptable for fermentation. Other types of organic waste slaughterhouse waste, fats, sludge from sewage treatment plants and stillage can be fermented too, but in this case there are some legislative problems. The biogas that is produced is used mainly for cogenerationi.e. for producing heat and electric energy.

Stillage should be neutralized before it is transported to a biogas plant. The most important considerations for a distillery are the distance between the distillery and the biogas plant, and the agreement between them. The shorter the distance to the biogas plant, the lower the transport costs and the more profitable the operation will be, because transport costs are the biggest part of all the costs. In our specific case, a biogas plant with sufficient capacity is assumed at a distance of $70 \mathrm{~km}$ from the distillery. One disadvantage of this method is the fact that fermentation of stillage takes a longer time than production of the same volume of stillage. Another factor is distance. The whole process line is drawn in Fig. 4.

This method seems to be financially attractive for distilleries, because the main costs are transport costs to the nearest biogas plant. The result of the calculation for this method is that the total operating costs (energy and transport costs) are $1410 €$ per daily production of stillage. The total operating cost for $1 \mathrm{~m}^{3}$ of stillage is $12 €$.

Advantages of this method:

- No investment costs (no evaporator, no dryer).

- Minimum requirements for modifying the original stillage.

- Potential savings in cogeneration of electric energy from biogas.

- No wastewater treatment requirement.

- The digestate can be used for fertilizing fields.

Disadvantages of this method:

- High transportation costs.

- Dependence on the nearest biogas plant, and dependence on biogas plants as a whole.

- Excessive damage to the environment and transport communications in the Czech Republic caused by trucks.

BIOGAS PLANT

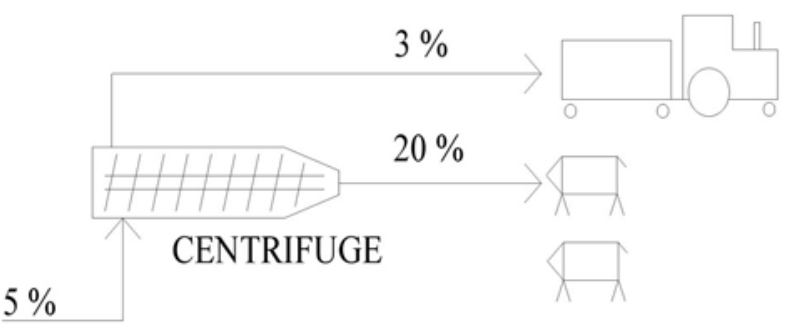

Fig. 4: Transportation of stillage to a biogas plant. Content of dry mass in wt. $\%$

Table 4: All operating costs of transportation to a biogas plant

\begin{tabular}{|l|r|l|r|l|l|}
\hline Total neutralization costs: & 170 & EUR/day & $7.0 \%$ & & \\
\hline Total cost - electric energy for centrifuge: & 60 & EUR/day & $2.5 \%$ & & \\
\hline Total transport costs of stillages: & 1810 & EUR/day & $74.5 \%$ & & \\
\hline Total transport costs of digestate to the fields: & 390 & EUR/day & $16.0 \%$ & & \\
\hline Total price of generated electric energy from biogas: & -1020 & EUR/day & XXX & & \\
\hline TOTAL OPERATING COSTS: & $\mathbf{1 4 1 0}$ & EUR/day & $100.0 \%$ & $\mathbf{1 2}$ & $\mathrm{EUR} / \mathrm{m}^{3}$ \\
\hline
\end{tabular}


Table 5: All operating costs for the chemical pre-treatment method

\begin{tabular}{|l|r|l|r|l|l|}
\hline Total cost - electric energy for centrifuge: & 60 & EUR/day & $5.2 \%$ & & \\
\hline Total cost - electric energy for mixing: & 5 & EUR/day & $0.4 \%$ & & \\
\hline Total price of chemicals: & 990 & EUR/day & $86.1 \%$ & & \\
\hline Total cost - electric energy for pump: & 30 & EUR/day & $2.6 \%$ & & \\
\hline Total transport costs of filtration cakes: & 65 & EUR/day & $5.7 \%$ & & \\
\hline TOTAL OPERATING COSTS: & $\mathbf{1 1 5 0}$ & EUR/day & $100.0 \%$ & $\mathbf{1 0}$ & $\mathrm{EUR} / \mathrm{m}^{3}$ \\
\hline
\end{tabular}

\section{Chemical pretreatment}

This method consists of a chemical pretreatment of stillage and then sending it to a waste water pretreatment plant (lagoons) to be cleaned up. This method is not used on an industrial scale yet, but it could be financially attractive for small and mediumsize distilleries in the near future. It is possible that this method will be used on an industrial scale soon.

According to [5]: "The heart of this method is the chemical precipitation of soluble organic and inorganic substances in stillage, their sorption on an acceptable carrier and their flocculation with organic flocculant. A significant reduction in the organic and inorganic substances contained in stillage can be achieved in this way. The final products are sedimented flocculus and pretreated liquid. The flocculus can be separated by filtration and the filtrate can be finally treated biologically in lagoons with aeration. In this way, the limits for safe outflow into a recipient (= river) can be achieved. The separated flocculus, together with the biological sludge, can be fed into a biogas plant."

During mixing and addition of substances A, B, C and D into stillage, flocculation (creation of flakes from organic and inorganic parts of stillage) takes place. This flocculated stillage is pumped using a suitable type of pump (a hydrostatic pump, or a membrane pump - the flakes cannot be disintegrated) into a filter presser (or into a belt dewatering line), where the flocculus is separated from the liquid phase. The concentration of the solid phase into a filter cake is about $20 \%$. This mass can be composted or fed into a biogas plant. The filtrate with solid phase concentration of about $0.2 \%$ can be treated in aerated lagoons. The whole process line is drawn in Fig. 5.

The most significant part of the operating costs are the expenses for chemicals, which are not specified. These costs constitute about $85 \%$ of all costs. The result of the calculation for this method is that the total operating costs (energy, transport costs and expenses for chemicals) are $1150 €$ per daily production of stillage. The total operating cost for $1 \mathrm{~m}^{3}$ of stillage is $10 €$. This is the cheapest of all the methods compared here. The main reason for the cost efficiency is the substitution of energy-demanding operations (evaporation, drying) by less energy-demanding processes (mixing and filtering).

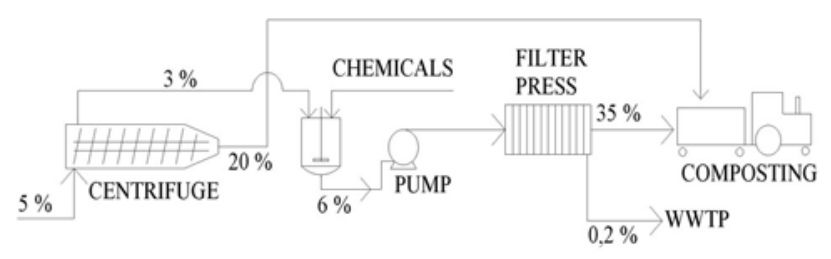

Fig. 5: Chemical pretreatment process line. Content of dry mass in wt. \%

\section{Advantages of this method:}

- Lower investment costs than in other methods (an evaporator or a dryer is more expensive than a mixing tank, a filter press and a pump).

- The possibility of filter cake composting.

- Low energy and transport costs.

Disadvantage of this method:

- High price of chemicals. They account for the main part of all costs.

\section{Conclusion}

The following conclusions may be drawn:

- A comparison of the operating costs for all methods is shown in Table 6 . The methods are listed according to increasing operating costs. The results are embodied in Fig. 6.

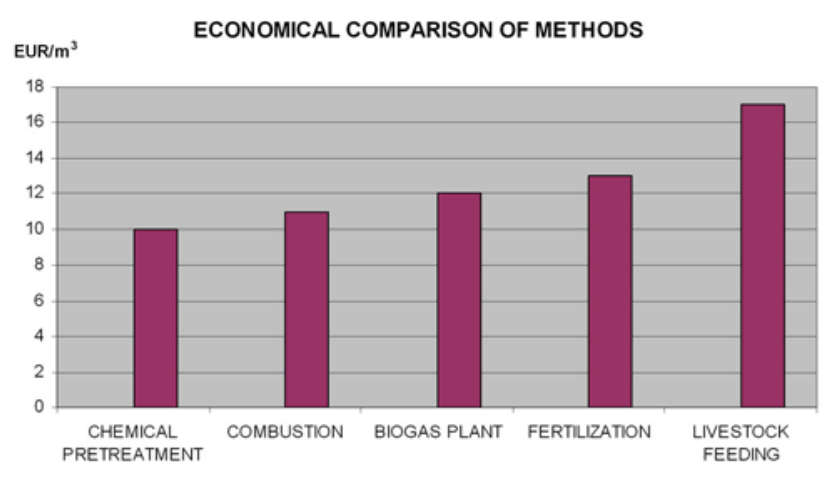

Fig. 6: Comparison of operating costs for all methods compared here

- According to the calculations presented here, the chemical pretreatment method appears to be the 
Table 6: Final comparison of methods

\begin{tabular}{|c|c|c|c|c|}
\hline DISPOSAL METHOD & $\begin{array}{c}\text { TOTAL } \\
\text { OPERATING } \\
\text { COSTS IN EUR } \\
\text { PER } 120 \mathrm{~m}^{3} \\
\text { OF STILLAGE } \\
\end{array}$ & $\begin{array}{c}\text { TOTAL } \\
\text { OPERATING } \\
\text { COSTS IN EUR } \\
\text { PER } \mathbf{m}^{3} \\
\text { OF STILLAGE } \\
\end{array}$ & & RANKING \\
\hline CHEMICAL PRETREATMENT & 1150 & 10 & $100 \%$ & 1 \\
\hline COMBUSTION & 1320 & 11 & $110 \%$ & 2 \\
\hline BIOGAS PLANT & 1410 & 12 & $120 \%$ & 3 \\
\hline FERTILIZATION & 1530 & 13 & $130 \%$ & 4 \\
\hline LIVESTOCK FEEDING & 2070 & 17 & $170 \%$ & 5 \\
\hline
\end{tabular}

cheapest in terms of operating costs. This method offers an interesting and cheap alternative to currently used disposal methods.

- The energy and financial calculations were based on a distillery with planned production of $120 \mathrm{~m}^{3}$ of stillage per day.

- The financial calculations cover operating costs, i.e. energy, transport and chemicals. The costs were determined at January $31^{\text {st }}, 2009$ prices.

\section{Acknowledgement}

This research has been supported by MŠMT of the Czech Republic Research Project MSM6840770035.

\section{References}

[1] Rosol, M.: Energy Optimisation of a Distillery. MASTER THESIS, Prague, 2007.

[2] Slabý, F.: Usage of Stillage from Bioethanol Production, PROKOP INVEST a. s., Pardubice, 2007. http://www.odpadoveforum.cz/symposium/ TextyOF/493.pdf ( $5^{\text {th }}$ August 2009)
[3] Párová, J.: Dry Complete Stillage from Bioethanol Production in Livestock Nutrition, Research Institute of Livestock Nutrition s.r.o., Pohořelice. http://www.keth.sweb.cz/Krmivo\%20vypalky.doc ( $5^{\text {th }}$ August 2009)

[4] Picka, J., Mariaca, E.: http://biom.cz/cz/ odborne-clanky/vypalky-ako-krmna-surovina, Tekro s.r.o. (5 $5^{\text {th }}$ August 2009)

[5] Nápravník, J., Ditl, P.: Modern Methods of Disposal of Pig Slurry. In: Actual Problems in Pig Breeding. Praha : Česká zemědělská univerzita, 2004, s. 79-91. ISBN 80-213-1176-2.

Václav Sajbrt

Ing. Martin Rosol

Prof Ing. Pavel Ditl, DrSc.

Phone: +420224352549

E-mail: ditl@centrum.cz

Czech Technical University in Prague

Faculty of Mechanical Engineering

Department of Process Engineering

Technická 4, 16607 Prague, Czech Republic 